\section{Influencing Behaviour for Crime Prevention through Architectural design and Construction: an Overview}

\section{Samuel 0. Ebong}

University of Uyo, Faculty of Environmental Studies, Department of Architecture Nwaniba Road, Uyo, Akwa Ibom State, Nigeria

*Corresponding author: samuelebong@uniuyo.edu.ng

$\Gamma$

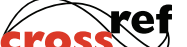

http://dx.doi.org/10.5755/j01.sace.19.2.18206
This paper discusses how architectural design could be used to manipulate the environment to influence behaviour for crime prevention. The method adopted is the review of existing literature and the qualitative approach of observation. Architects are unavoidably involved in influencing behaviour of users and abusers of the built environment through their designs. The elements of architecture are subject to complete control and manipulation by the architect. Architectural design for crime prevention is a design process with the explicit intention to influence behaviour. The paper maintains that in designing with the intention to influence behaviour, the designer should focus on the intended behavioural outcome in order to create a particular experience and influence user and abuser decisions. The key to designing to influence behaviour is strategic thinking. This paper therefore advocates strategic (extended) thinking as a means of arriving at a creative solution that addresses security challenges. The uniqueness of this method is that it helps the architect to understand the attacker's methods, approaches and tactics and how to defeat them in order to create a defendable facility. It concludes that design to influence behaviour could be achieved if the architect has knowledge of crime prevention design concepts, theories and principles, the basic technology and types of crime prevention systems, products, and the process involved in integrating security and design. It recommends that architects become involved in the study of behavioural setting of a project site in order to expand the scope of programming to include and address social issues, such as crime, in their designs.

Keywords: influence, behaviour, crime prevention, architectural design, construction.

Ahmadi et al (2015) observe that the built environment influences human behaviour. They argue that its design can encourage offenders to commit crime by creating the opportunity for crime and it can prevent crime with increase of residents' ability to monitor the environment. Architects are unavoidably involved in influencing behaviour of users and abusers of the built environment through their designs. Teeuw and de Boer (2011) opine that the most apparent method of influencing behaviour is direct physical measures through design. Arguing further, the design of the environment for effective surveillance, access control and territorial control can be used to enforce safe behaviour to counter crime. Crime prevention through environmental design (CPTED) is dependent on an inclusive design process involving architects, urban planners, clients, community, security experts and law enforcement professionals. Its strategies are aimed at influencing a would-be offender's decision before a criminal act (Crowe and Fennelly, 2013, Atlas, 2013). It is

\section{Introduction}

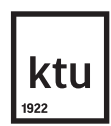

Journal of Sustainable Architecture and Civil Engineering Vol. 2 / No. 19 / 2017 pp. $5-12$

DOI 10.5755/j01.sace.19.2.18206 (c) Kaunas University of Technology 
focused on manipulating the built environs to deny criminal opportunities by increasing the risk and reducing the ease and reward factors. This is based on the premise that the environment emits some cues that influence the offenders' target selection process. It is also intended to make citizens feel safer by reducing the fear of crime.

A study by Pirbasti et al (2015) indicate that design can create "an environment that can encourage normal behaviour and discourage unwanted ones." However, a different perspective suggests that criminal adaptation to anti-crime design measures diminishes the ability of "environmental factors to influence behaviour thereby questioning the CPTED premise of using design to influence criminal behaviour" (Mckay, 2015). It raises the question: How can design be used to address criminal adaptation and behavioural change? Schneider et al. (2013) drawing from experiences from a research-based design studio suggest that building designs require that architects consider future users and try to predict the likely pattern of use and abuse of a building. This paper agrees that design should, therefore, evolve to address new criminal behaviour as it relates to tactics, tools and weapon since, as observed by Mckay (2014), "human behaviour is not static but always evolving."

The key, therefore, is to apply strategic thinking during the design process as a means of arriving at solutions that address the security challenges. Strategic thinking involves thinking outside the usual architectural box to find solution to crime prevention and intricate security challenges. It involves designing with the holistic understanding of the potential threats and risks to a proposed facility. For example, from 1934 - 1945, the Japanese army needed to construct underground inter-connected fortresses along Chinese-Russian border in north east China to accommodate hundreds of thousands of military personnel and several arms and food storage facilities. The challenge to the architect and the design team was not only the design of such massive underground facilities but lighting, sanitary and ventilation systems and most importantly entrances and exits that could not be detected or discovered. In order to solve this intricate security challenge the design team had to think strategically in military and security terms. This was accomplished and some of the fortresses were discovered only at the end of the Chinese-Japanese war in 1945. Different types of construction and their application in different combinations were used. Strategic thinking involves understanding the attackers' methods and how to defeat them. Such methods include moving and stationary vehicle bombs, suicide bombers, use of petrol bombs, grenades, standoff weapons such rocket propelled grenades (RPGs), use of light arms, assault rifles and high-powered sniper rifles. It also includes use of special cutting equipment and blow touches to create man-passable holes, clandestine entry, tail gating and sometimes the use of chemical and biological weapons. This calls for more than basic security design thinking of fence, burglary proof, security doors and installation of close-circuit television. It calls for thinking creatively and strategically in order to create a defensible facility that minimises opportunities for the threat to manifest.

The products of architecture by implication must not only be beautiful and of sound construction but must have intellectual content. Great architectural works, principles and theories have always generated great discourse and debates because of their ability to draw from and build upon precedents and other fields of study. The basic elements of architecture are subject to complete control by the designer. As an artist, the architect decides the precise shape, size and proportions of a building, roof, columns and walls and spaces. As a scientist he engages technology in adapting these elements. For example, artificial light can be controlled to achieve different effects on the building elements, spaces and people. It can be used as a security element to create deterrence effect. Other building materials can have their texture, strength and qualities elaborately improved and enriched through technology to achieve different purposes, including crime prevention. This paper discusses how architectural design and construction elements could be used to manipulate the environment to influence behaviour for crime prevention. 
Two methods are adopted for this work. First is the review of literature to help situate the paper. Secondly, the qualitative method of observation is used to help to practically support the concepts. The observations were documented as photographs. Qualitative data is more concerned with meanings and also enables the use of literature as an important source in helping to find probable clarifications of the phenomenon of study (O'Conor and Gibson, 2003).

Architectural design begins with the site. The site is a crucial aspect of environment. It communicates challenges and opportunities, limits what can be done on it and also opens new possibilities. The site is the first contact that one has with any architectural project before one can access the building. Therefore, in planning and designing the site for security the following should be considered, namely, placement of structures on the site, location of functions and shaping the spaces in order to influence behaviour and achieve the objectives of the project.

Architectural design is the process of deliberately creating and shaping spaces. Flusty (1997) sees crime prevention design as the process of creating 'interdictory spaces' to influence behaviour. These are spaces designed to intercept and ward off or screen and sort out would be users. He identifies five types of interdictory spaces as follows: (i) stealthy space - areas deliberately hidden from general view; (ii) slippery space - those without visible means of approach; (iii) crusty space - those that cannot be accessed because of obstruction; (iv) prickly space - uncomfortable space due to measures inhibiting activities; and (v) jittery space - space under constant observation, both positive and negative. The choice and design of these spaces depend on the design and security objectives which in turn depend on the purpose of the project and the risk profile of the users. All buildings create social activity due to their proposed function, interactions and the sometime random encounters that they generate. The planning and design of activity and circulation spaces can encourage or hinder interaction which can occur at any number of points. The architect or designer can decisively control the extent that he designates the points of contact or interaction.

This involves broad strategies and specific tactics which can be expressed architecturally. Practically, most behaviour influencing architectural patterns involve the physical arrangement of internal and external building elements and/or a change in material properties (Lockton, 2011). Arrangements, positioning and layout of spaces and building elements are crucial in determining the kind of behaviour to influence. For example, barriers could be put in people's way to hinder access to a particular area; pedestrian or vehicular traffic could be channelled or directed in a particular direction by strategic placement of site elements and surveillance could be enhanced by strategic placement of windows, openings and location of trees. It is necessary for architects to aspire to produce buildings which are not only attractive, functional and up-to-date but that can influence positively user attitudes and behaviours. The crime prevention architectural design process can be driven by the following, individually and collectively: (i) explicit intention to influence behaviour, (ii) behaviour consequences revealed by design decisions made in previous projects, and (iii) impacts of previous projects on crime. In designing with the intention to influence behaviour, the designer should focus on the intended behavioural outcome, for strategic reasons, in order to create a particular experience and influence user decisions. Architectural design for crime prevention is a design process with the explicit intention to influence behaviour that draws from previous design decisions and projects. Seven steps are required in order to design to influence behaviour for crime prevention. These are, establish and analyse the client's brief in terms of goals and objectives, define the problem, analyse site, analyse users, carry out design programming, specify and incorporate appropriate products and mechanisms, and develop final design.

In defining the problem several questions should be asked and answered: Where is the project to be located? What is the purpose of the project? What are the objectives of the project? Who are the users? What are the requirements? What resources are available? What is the expected solution or design outcome? In analysing the site, the essential character of the site and patterns of activities

\section{Methods}

Influencing
behaviour
through
design


(legitimate and illegitimate) in and around it should be carefully considered. It is also necessary to analyse the users to understand the risk pattern of the users. In every facility there are risk to users and risk from users. According to Atlas and Hopper (2007), the basis for a creative security design is an accurate risk assessment. In the formal design process programming is more concerned with the technical aspects of the pre-design investigations such as site, spatial, cost and regulatory analysis. Little is done in investigating behavioural settings, such as crime, that can best address real human needs, conditions and requirements. According to Horayangkura (2012), programming provides the opportunities to incorporate the necessary information inputs of the users and social context of the design. Programming for design requires an analysis of existing projects (case studies) for success patterns, population profile, site usage, package of activities, constraints, failures of physical arrangements and performance. Listed objectives should be translated into performance statements, requirements and design assumptions. The identified problem should be framed from different perspectives with the help of experts (security, engineering, law enforcement).

Incorporating the 4Ds of crime prevention into design to influence behaviour

\section{Fig. 1}

These bank building access control doors in Abuja, Nigeria promote deterrence, delay and detection. Photograph by the author
Security design is the process of incorporating a project's crime risks, vulnerabilities, security measures required and an assessment of where these measures are required into the design. A good and pro-active security design must address the 4Ds of crime prevention - deter, delay, detect, and deny access for unauthorised entry.

Deterrence is a psychological approach that is directed at the decision-making process of the criminal with the intension of making him/her to decide against a criminal act. Deterrence in security functions through the concept of fear-changing behaviour through the fear of being apprehended and punished. Fear strongly affects human behaviour and the fear of punishment has a strong sobering effect on an individual's survival instinct. This concept of fear has been used variously by parents, schools, religion and governments, when necessary, to produce an expected form of behaviour. Many of the physical measures adopted have psychological effect. Lighting is a physical security measure which cannot stop crime. It aids surveillance. A well-lit environment registers in the mind of an intruder that the chances of being seen and caught is higher than in poorly lit environment. A number of studies carried out in a variety of settings indicate that there is ample evidence that improved street and external lighting are effective in reducing property crime significantly (Welsh and Farrington, 2006, 2009). Various other means such as physical barriers, access control, CCTV, fences, doors and warning signs attain this effect. Available evidence also suggests that the effectiveness of CCTV in deterring crime depends on the extent to which peo-

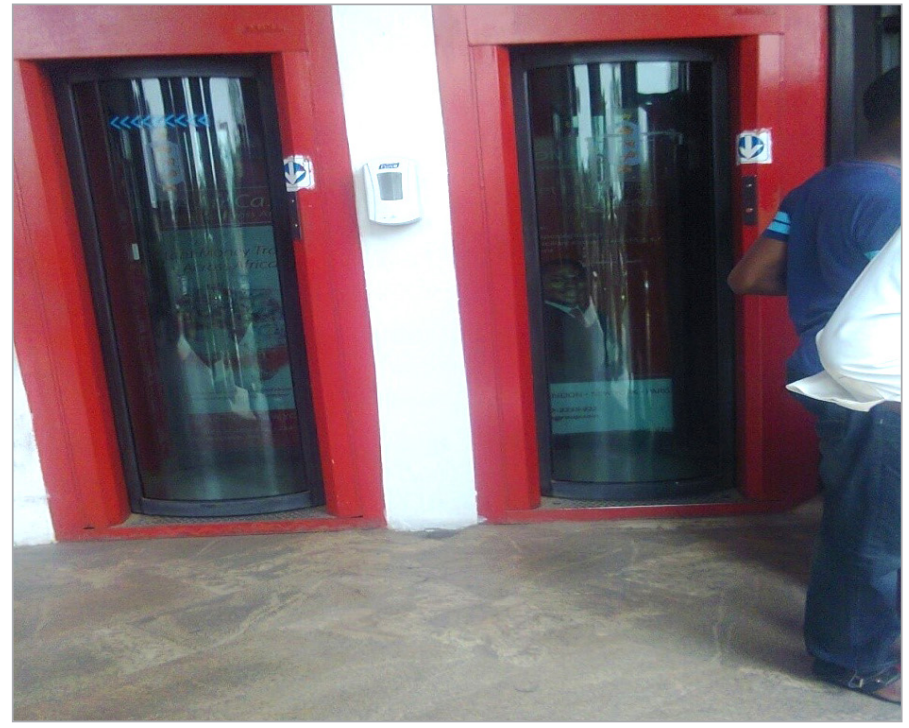

ple are aware of its existence (McLean et al., 2013). Fig.1 shows a building access control mechanism. This mechanism allows only one-person access at a time. It is configured to detect metals and therefore is useful for screening people for weapons as the inner door does not open when a metal is detected. This enables the security personnel to search the person if it becomes necessary. It acts as both deterrence and delay measure.

Delay is another principle of 
crime prevention which gives security personnel the needed time to respond to a threat situation. The design principle is to increase the effort and make it more difficult for the intruder to commit the crime. One strategy to attain delay is to provide different layers of security working together to create a defence depth. Physical security practitioners have identified three lines of defence. These are the site perimeter as the first line of defence, the outer building walls as the second line of defence and the internal building spaces as the third line of defence (Federal Emergency Management Agency, 2007; Atlas and Hopper 2007). Perimeter control is achieved through the use of fence, wall, guards, gates and closed circuit television. The perimeter should be well defined to make it distinguishable to both legitimate users and intruders thereby creating zones of influence (Fig. 2).

The establishment of a hierarchy of spaces (zoning) can also help to achieve an effective layer of defence to accomplish the principle of delay. Properly designed and designated zones will allow proper levels of physical and psychological controls based on the risk and vulnerability assessments. For zoning to be effective risks to and from a particular group of users should be determined. Movement pattern of each risk-categorised user group should be traced. For example, employees require less degree of control and verification than visitors. Access control which is a method of delay in physical security should be carried out at designated areas. Design can channel users to these security screening points which are points of transition from one zone to another. The numbers of these transition points depend on site layout, positioning of building and interior space function and layout. Vehicular access control measures are shown in Fig. 3. It shows how vehicle speed control mechanisms are combined with

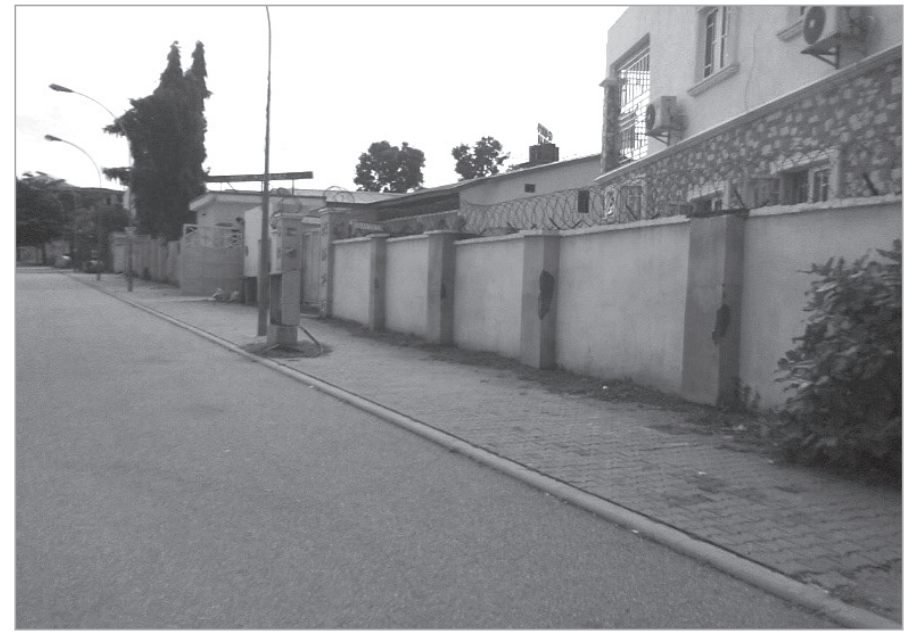

Fig. 3

Comprehensive Vehicle Access Control System. Scheme by the author 


\section{Fig. 4}

The gate to United Nations House, Abuj brought down by a bomb-laden vehicle before ramming into the building. Note that there is no vehicle access control system (Marama, 2011)

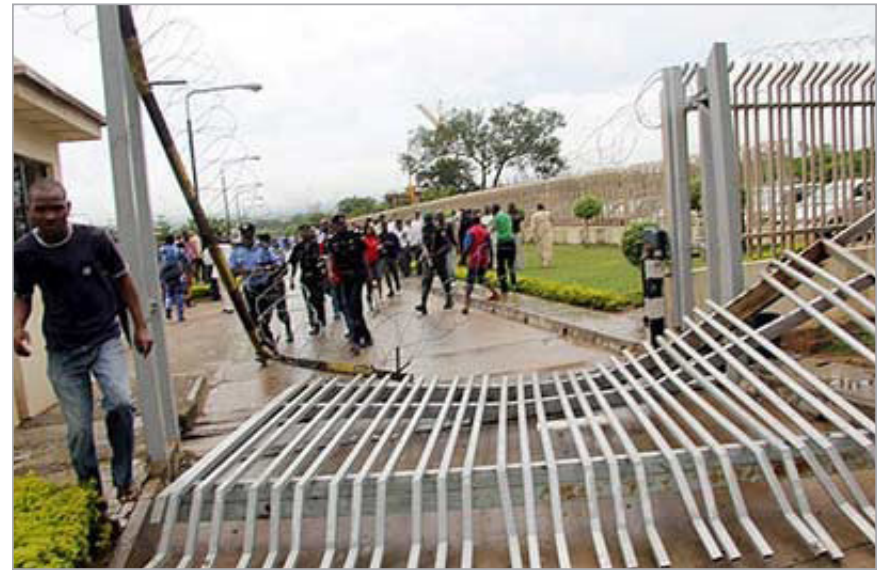

Fig. 5

Gate house to Akwa Ibom State House of Assembly, Uyo, Nigeria.

The windows allow observation of areas outside the gate with clear lines of sight. Photograph by the author

Fig. 6

Gate house in High Court Complex, Moore Road, Calabar, Nigeria shows design and construction without windows and/ or openings for natural surveillance of road and parking areas thereby creating blind spots that could lead to security compromise. Photograph by the author

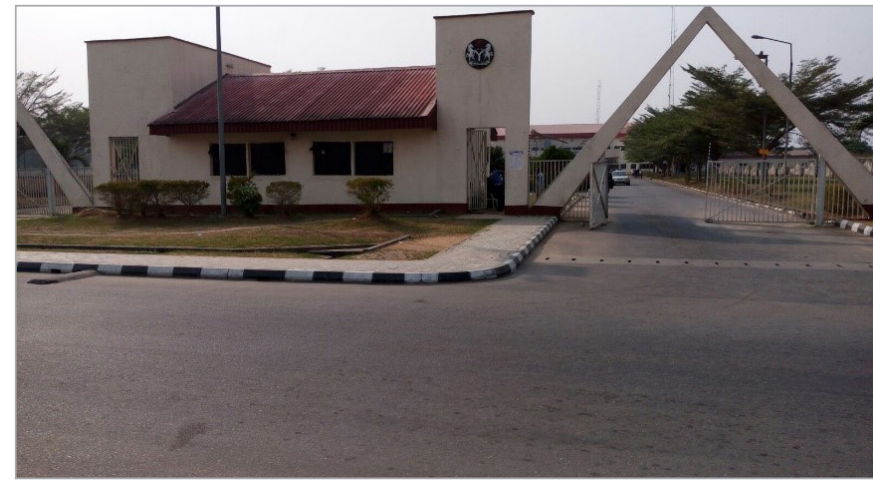

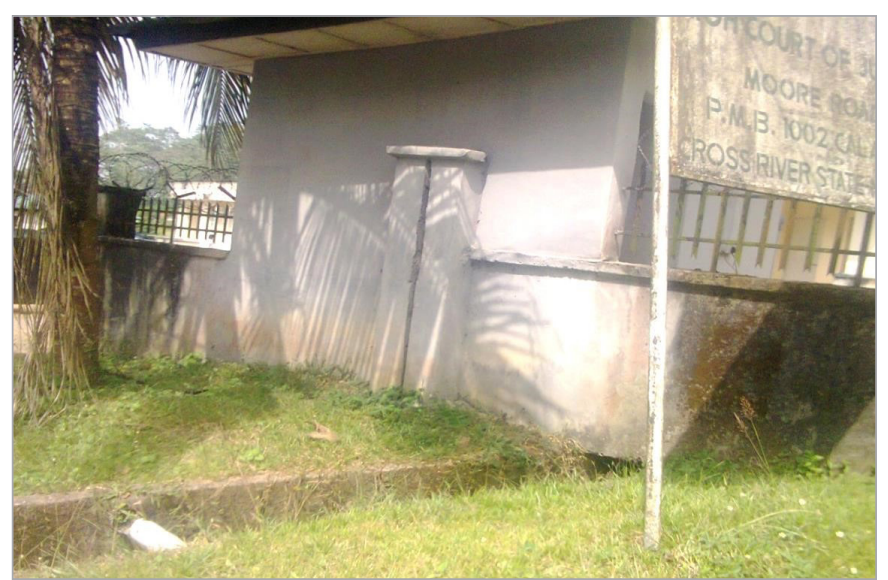
out designated functions while linkages are the paths, routes and connections between these user function areas. The alignment and positioning of activity areas and linkages greatly affect the lines of sight need for effective surveillance. Sight lines can also aid negative or hostile surveillance. This allows criminals lines of sight to a potential target or targets. Elevated sites may allow observation and monitoring of lower areas by adversaries. Lines of site can be blocked to avert hostile surveillance using design elements. CCTV is the most commonly used mechanical method of detection. A study by Levesley and Martin (2005) suggests that instead of preventing crime its strength lies in its capacity to "proactively detect crime incidents" when monitored real time.

The ultimate aim of physical security is to deny access to would-be assailants. This is done by human and physical means. Guards provide the human means of denying access to intruders. 
Barriers are the physical means that enhance the defence of a property. Barriers function by target hardening of vulnerable areas (Fig. 7) and by channelling users away from unauthorised areas to designated control points. Barriers vary according to intended security usage and function.

There are three main types of barriers, namely: vehicle, people and screening barriers. Vehicle and people barriers restrict movement to only designated areas while screening barriers such as fences, walls and tall planting (hedges and shrubs) prevent potential offenders from gathering information to aid their operations. According to Brodie (2005), barriers are effective in shielding a target from observation by criminals, in deterring, delaying or stopping an aggressor, or in mitigating the force, strength and severity of an attack. Barriers can aid circulation and channel traffic (Fig. 8), serve as obstacles and aid in controlling vehicular speed. It can also help to decrease the kinetic energy of a vehicle, especially vehicles with explosive devices. The use of blast resistant doors, windows and other building structural members decreases damage to property and loss of life due to explosion. Effective barrier deployment and placement can
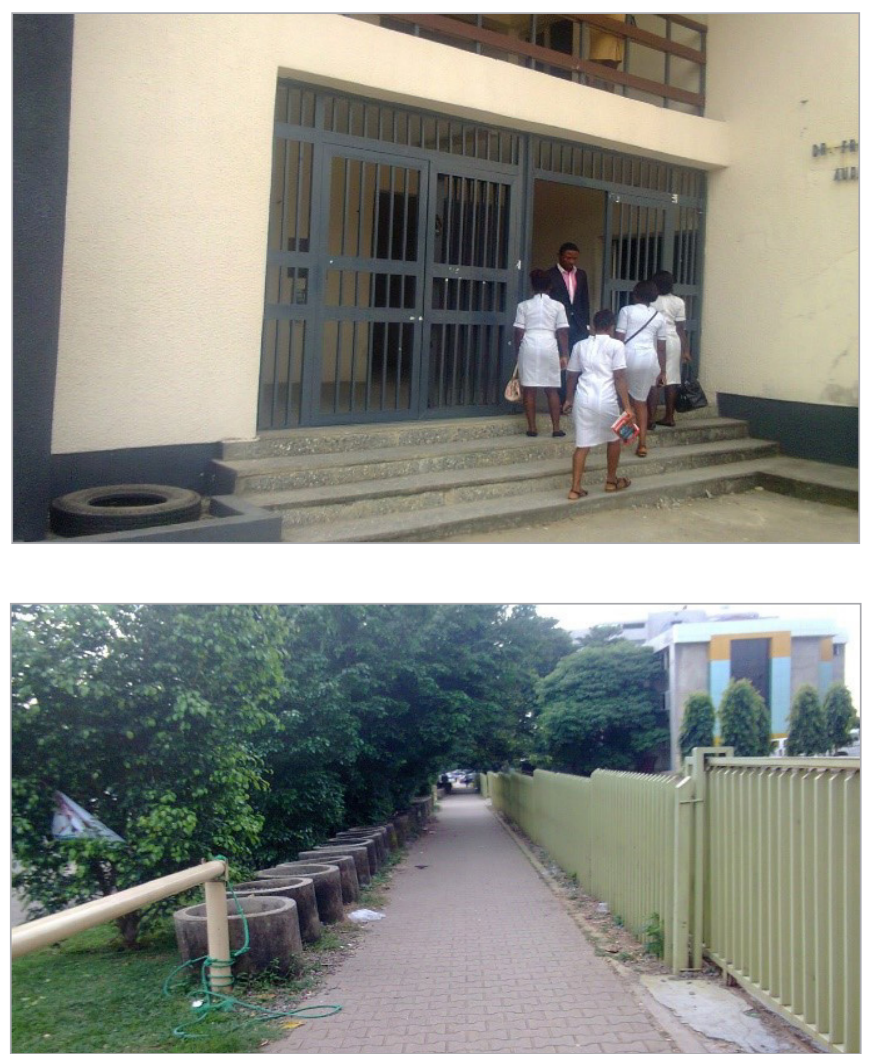

only be done in tandem with the overall security objectives which take into consideration the risks and vulnerability assessments of the building, site and users.

This paper drew attention to the fact that the design of the built environment has the capacity to influence behaviour either positively or negatively. It noted that in influencing behaviour for crime prevention the architect needs to consider criminal adaptation to existing methods and adopt strategic measures to stay ahead of the criminal.

Architects can use the defensible space concepts of territorial control, access control and surveillance, among other methods, to enforce behaviour that can counter crime. The design and layout of spaces and the physical arrangement of site and building elements is the key to influencing behaviour for crime prevention.

The goal of the architect should be to design secure and safe buildings. This can only be carried out effectively if the architect has knowledge of crime prevention design concepts, theories and principles, the basic technology and types of crime prevention systems and the process involved in integrating security and design to influence behaviour.

This paper recommends that architects become involved in the study of behavioural setting of a site in order to expand the scope of design programming to include and address social issues in their designs. Further research is needed on ways to counter criminal adaptation.

\section{Fig. 7}

Metal burglary proof entrance door used as target hardening measure to provide delay and denial of unauthorised access to classrooms in a health institution in Calabar, Nigeria. Photograph by the author

Fig. 8

Engineered planters and metal fence used to restrict vehicular access and channel pedestrian traffic to access point at a school in Abuja, Nigeria. Photograph by the author 
Atlas R. 21 st century security and CPTED: designing for critical infrastructure protection and crime prevention. Boca Raton: CRC Press; 2013. https://doi. org/10.1201/b15046

Atlas R., Hopper L. J. Security considerations: crime prevention though environmental design. In Landscape architectural graphics standards (students ed.). Hopper, L. J. (Ed.). New Jersey: John Wiley and Sons, Inc.; 2007.

Ahmadi B., Afrouz M. and Hashemi M. Applying environmental design approach (CPTED) to improve security in urban worn out texture; case study: Urmia downtown, Iran. Journal of Civil Engineering and Urbanism, 2015; 5(2): $94-101$

Brodie T. G. Bombs and bombings: a handbook of protection, security, detection, disposal and investigation for industry, police and fire departments. 3rd ed. Springfield, IL: Charles C. Thomas Publishers Ltd; 2005.

Crowe T. D. and Fennelly L. J. Crime Prevention through environmental design. 3rd ed. New York: Elsevier; 2013.

Federal Emergency Management Agency. Reference manual to mitigate against potential attacks against buildings (FEMA 426). New York: FEMA; 2003.

Flusty S. Building paranoia. In, Ellin, N. (ed.), Architecture of fear. Princeton: Architectural Press; 1997.

O'Conor H., Gibson N. A Step-by-step guide to qualitative data analysis. Pimatiziwin: Journal of Aboriginal and Community Health, 2003; 1(1): 63 - 91.

Horayangkura V. Incorporating environment-behaviour knowledge into the design process: an elusive challenge for architects in the 21st century. Procedia - Social and Behavioral Sciences, 2012; 50: 30 - 41. https://doi.org/10.1016/j.sbspro.2012.08.013

Levesley T., Martin, A. Police attitude to and use of CCTV. Home Office On-line Report 09/05, 2005; Retrieved from Https://www.homeoffice.gov.uk/rds/ pdfs05/rdsolr0905.pdf

Lockton D. Architecture, urbanism, design and behaviour: A brief review, 2011; Retrieved from www. danlocton.co.uk
Marama N. UN House bombing: Why we struckBoko Haram, 2011; Retrieved from http://www.vanguardngr.com/2011/08/un-house-bombing-whywe-struck-boko-haram/

Mckay T. Focusing on behaviour will benefit design, 2015; Retrieved from https://www.publicsafety.gc. $\mathrm{ca} / \mathrm{cnt} / \mathrm{rsrcs} / \mathrm{lbrr} / \mathrm{ctlg} /$

McLean S. J., Worden R. E., Kim M. Here's looking at you: an evaluation of public CCTV cameras and their effects on crime and disorder. Criminal Justice Review, 2013; 38(3): 303 - 334. https://doi. org/10.1177/0734016813492415

Pirbasti M. Y., Azari A. R. and Shirchi F. The influence of urban design in preventing and reducing the amount of crime and raucousness and the delivery of sense of security (Lalijan as a Case). Current World Environment, 2015; 10 (1): 474 - 483.

Schneider S., Kuliga S., Hölscher C.,Conroy-Dalton R., Kunert,A., Kulik A., Donath D. Educating architecture students to design buildings from inside out: experiences from a research-based design studio. In, Kim Y.O., Park H. T., Seo K. W. (eds), Proceedings of Ninth International Space Syntax Symposium. Seoul: Sejong University; 2013.

Teeuw W. and de Boer J. Influencing behaviour for safe working environment. Enschede, The Netherlands: Saxon Research Centre for Design and Technology; 2011

Welsh B. C. and Farrinton D. P. CCTV and street lighting: comparative effects on crime. In, Perry A. E., Mcdougal C. and Farrington D. P. (eds), Reducing Crime: The effectiveness of criminal justice interventions. Chichester: John Wiley; 2006.

Welsh B. C. and Farrinton D. P. (2009). Public area CCTV and crime prevention: an updated systematic review and meta-analysis. Justice Quaterly, 2009; 26(4): 716 - 745. https://doi. org/10.1080/07418820802506206

\section{About the author}

\section{SAMUEL O. EBONG}

\section{Lecturer}

Department of Architecture, Faculty of Environmental Studies

\section{Main research area}

Construction management; Anti-terrorism, crime prevention and security design

\section{Address}

University of Uyo, Uyo, Nigeria

Tel: +2348023144366

E-mail: samuelebong@uniuyo.edu.ng 